\title{
Diseurso do Diretor Geral por ogasião da formatura do Bacharelado em Teologia da FACASC
}

\section{Edinei da Rosa Cândido}

Saudações às autoridades acadêmicas componentes da mesa, a D. Jacinto Inácio Flach, paraninfo e padrinho de turma, convidados dos formandos: pais, mães, demais parentes e amigos; membros do CONSUPE reunidos em caráter extraordinário para este importante evento acadêmico de colação de grau, senhoras e senhores, bom dia.

Na última segunda-feira, 09 de dezembro, quando estivemos aqui nesta sala para ensaio deste ato, dei-me conta de que estava, após muitos anos, revisitando um ambiente familiar. Esta casa é, de longa data, de muitos dos presentes conhecida: Educandário Imaculada Conceição. Entretanto, este recinto trouxe-me boas recordações. Parecia ser ainda o mesmo palco, e o revestimento em lambri escuro das paredes, já não deixava dúvidas de que estava no salão nobre desta escola; e a importância não era pequena. De fato, neste mesmo auditório, em agosto de 1991, reuni-me com grande concurso de pessoas. O evento era importante e atraiu a atenção da imprensa que, na mesma noite, o noticiou em rede nacional.

Naquela memorável noite, tive a alegria de lançar meu primeiro livro, cujo título dispensa grandes comentários e bem denota a importância e, claro, a justificativa da atenção da imprensa: O milagre do amor: Vida, Milagre e Beatificação de Madre Paulina. Vivia-se a euforia da preparação à segunda visita de Sua Santidade o Papa João Paulo II ao Brasil, primeira e única a Santa Catarina. Nada mais justo que o fato colhesse as boas graças de muitos.

Quantas linhas mais poderiam ser acrescentadas a estas! Bastaria recordar o fato de o Papa vir ao Brasil e a Santa Catarina para beatificar a Madre Fundadora da Congregação das Irmãzinhas da Imaculada Conceição e o milagre canônico, reconhecido pela Igreja, ter se dado

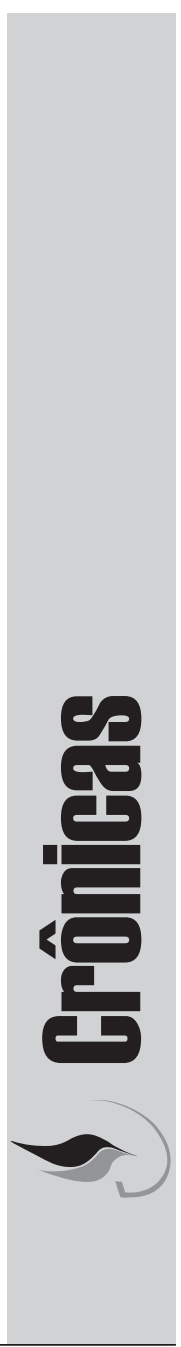


no seio de minha própria família, tendo por protagonista, minha própria tia, irmã mais moça de minha mãe, Eluiza Rosa de Souza, a miraculada. Realmente, muitas linhas poderiam ser acrescentadas a estas. Memorável aquele 18 de outubro de 1991, Beatificação de Madre Paulina! (Tive a honra de, ao almoço estar ao dispor do egrégio pontífice e, para regozijo da doceira, pude testemunhar-lhe: "o Papa papou papo de anjo duas vezes". A frase, efêmera, virou legenda e, alvissareira, correu de boca em boca entre os atabalhoados serviçais daquele seleto prândio.)

Além de minha própria pessoa, então seminarista do segundo ano de Teologia, duas outras entre nós podem testemunhar o fato: o então reitor do seminário de Teologia, Professor e diretor do ITESC: Pe. Vitor Galdino Feller e outro, também Professor do ITESC e Coordenador Geral da visita do Papa João Paulo II a Florianópolis, Pe. Vilmar Adelino Vicente, ambos aqui presentes.

De lá para cá, muita coisa mudou: Madre Paulina foi beatificada, canonizada e a santidade de muitas outras mulheres e homens foi reconhecida pela Igreja. Recorde-se, por exemplo, Irmã Dulce, Santa Dulce dos Pobres canonizada neste último mês de outubro, dia 13. De lá para cá, muita gente ficou santa, inclusive o próprio presidente da missa de Beatificação, daquele 18 de outubro de 1991, São João Paulo II.

Para nós três professores, voltando a atenção aos pequenos, e para nossa trajetória comum entre os mortais, recordo o provérbio: pedra que muito rola não cria limo! Acho que somos pedras que não rolam. Por isso, continuamos no mesmo lugar, sem perspectivas de deslocamento. Algo, porém, mudou: o ITESC agregou a FACASC e é em seu nome que estamos aqui para este ato solene, a colação de grau deste ano de 2019, desta turma de 2016 .

O momento é especialíssimo para este vitorioso grupo, ostentando feliz o diploma e o barrete dos laureados. Afinal é o coroamento de tantos anos de estudo e preparação, o brevê para alçar condoreiros voos. Para mim, igualmente, este cerimonial tem um sabor especial; é o último ato acadêmico público dos últimos dias deste nada pacato ano de 2019, concluindo o quarto e último ano, pacato, desta gestão. É uma ótima oportunidade para a devida revisão de mandado, prestação de contas e todo o restante do que é de praxe para estes momentos. Aliás, seria..., pois prefiro deixar a subjetividade do lugar-comum das planuras e, apoiado no sonho juvenil destes formados, alçar, com as asas da fé, amparado 
pelas asas da razão, neste caso astronômica, voo, para, além de todas as esferas e fora desta órbita, contemplar as alturas.

Sonhar não é proibido, pelo contrário, é desejável, é deixar o pensamento e o coração se dilatar; sonhar é acordar por dentro, diz o poeta. O ser humano nunca deixou de sonhar na terra e, há cinquenta anos, talvez cansado desta experiência que se lhe tornara corriqueira, resolveu desafiar o espaço sideral e transformar sonho em realidade: viajar até a lua, pisar na lua, andar na lua, conquistar a lua. Foi uma façanha inimaginável aquela jornada de 21 de julho de 1969.

Muito se especulou sobre os recursos tecnológicos de então que permitiam um tamanho prodígio: foguetes, capacetes, espaçonaves (a legendária Apolo 11!) e módulos lunares (já se começava a sonhar para além da via láctea e outras galáxias). Enquanto os três pioneiros, Neil Armstrong, Michael Collins e Edwin (Buzz) Eugene Aldrin, lá chegavam, aqui na terra o planeta congelava boquiaberto diante das telas de televisão. O alvoroço cá foi grande, e muitas histórias envolvendo essa odisseia da trajetória humana foram pouco exploradas, algumas ainda não foram contadas e outras sequer conhecidas.

Dentre todos os detalhes daquela chamada missão lunar, um passou quase desapercebido: antes que o grupo, recém-chegado, fizesse a primeira refeição, café com bolo e bacon, pêssegos e suco de uva, Aldrin abriu, preparado com muita cura, o seu curioso fardo a ele confiado pelo reverendo de sua igreja: era um pouco de pão e um pouco de vinho, granjeados no Domingo anterior à partida. Era sua primeira refeição no espaço. Naquele momento, bem longe da terra, na lua, abraçando o universo, ele deu graças, fez memória daquele encontro em sua comunidade que lhe propiciara aquela preciosa reserva eucarística. Em seu coração ardia a ternura e o calor, a vibração da fé dos irmãos, e acendeu-lhe n'alma o desejo profundo de estar reunido em nome do Senhor, no dia do Senhor. E ele fez memória da última ceia, da santa ceia, da ceia do Senhor.

A espaçonave aterrissou, o homem chegou à lua, o cristão celebrou. Eram duas velhas amigas siderais. Separadas por muitos anos luz, fitando-se à distância, ansiando-se por se encontrarem. Lua e terra finalmente se abraçavam. O universo parou, até os incrédulos pararam, os ateus, os agnósticos, os céticos do cientificismo ufanista, todos, tudo parou e o universo, estarrecido, contemplou essas duas criaturas plasmadas por um mesmo e único criador. 
O fato extraordinário pede o olhar do teólogo. De há cinquenta anos para cá, como ao longo de toda a história, os fatos se sobrepõem à experiência humana, comunitária, política, social, e a Teologia continua a sua investigação, buscando responder a cada nova realidade. $\mathrm{O}$ olhar do teólogo há que ser constelar.

Deixando as alturas siderais e descendo às planuras terreais, mas sempre seguindo o norte da bússola, caminhamos ao encontro de outra ocorrência quase cinquentenária. É menos colorida e tecnológica, contudo, a celebração dos cinquenta anos do Regional Sul IV da CNBB, abrangendo exclusivamente o território catarinense, apresenta-se como oportunidade preciosa de reflexão. Sua condição de representação local estadual da Igreja no Brasil projeta-o como instrumento catalisador de propostas, iniciativas e carismas.

Do muito que essa instituição tem promovido na colaboração com a ação da Igreja em nosso Estado, gostaríamos de destacar o que está mais especificamente voltado à formação teológica. São muitas as ações nessa área e a Fundação Dom Jaime de Barros Câmara agrega, na condição de mantenedora, três instrumentos de importância fundamental: ITESC, SEFISC, FACASC. Incidindo mais na especificidade da formação em vista do ministério ordenado, de prevalência presbiteral, mas também diaconal e, remotamente, episcopal. (Importante destacar que a proposta do protagonismo leigo é uma realidade que penetra cada vez mais nesses ambientes, exclusivos do clero, no passado, e usufrui, em progressiva escalada, dos seus benefícios formativos).

Além destas, outras instituições, com maior autonomia, gravitam na órbita do estado catarinense e ainda outras esperam poder ver a luz do dia. Todas são instituições direcionadas para o magistério superior, graduação e pós-graduação, e têm a sua utilidade. Entretanto, compassos e descompassos impedem, por vezes, que cada qual encontre o seu espaço, realize o seu específico e alcance o seu objetivo.

$\mathrm{O}$ futuro imediato de muitas dessas iniciativas parece incerto; existe desconfiança e uma espécie de temor velado paira sobre o horizonte. Qual é a proposta da Igreja de Santa Catarina em termos de formação superior, filosófica, teológica, diaconal, permanente, para o presente e os próximos anos? O que se está semeando nesse sentido? Qual o papel e a viabilidade dessas instituições citadas e de outras não-citadas? Existe 
excesso de oferta para a realidade da procura? Ao ser criada, instituída e instalada cada uma delas pensa-se nas outras? Estamos somando esforços ou dispersando energias? Existe consciência de fraternidade com suas implicações na unidade?

A harmonia sofre o ruído da desafinação. E aqui bem vale lembrar as belas metáforas de Santo Inácio de Antioquia que, embora remontem ao segundo século do cristianismo, convida-nos a uma sinfonia de diversidade instrumental. É preciso não perder a consciência de que se pisa um chão que predecessores, a duras penas, palmilharam, conquistaram e nos legaram.

Basta com alturas, planuras e agruras!

Queridos teólogos, saúdo-os já como ex alunos da FACASC, tivemos a alegria de caminhar quatro anos juntos, eu na penosa função de Diretor Geral e vocês na privilegiada condição de alunos. Esta cerimônia encerra uma etapa preciosa de nossas vidas e portas espalmam-se a nossa frente; novos caminhos deverão ser trilhados. Renovo, mais uma vez, os agradecimentos já expressos na missa de encerramento das atividades acadêmicas celebrada no último dia 05 . Usufruindo mais uma vez dos benefícios desta casa, expresso meus agradecimentos, em recordação, à Irmã Justina Cristofolini, diretora em 1991 e à Irmã Kelli Amorim, diretora atual.

Este também foi um chão palmilhado e conquistado com muito suor... Para cá vieram as Irmãzinhas da Imaculada Conceição em maio de 1942, com o propósito de fundar uma obra dedicada à catequese. O protagonismo de Madre Maria Josefa, primeira superiora desta casa, ainda permanece na memória de algumas pessoas de nossas comunidades da Ilha. E esta foi a última fundação que a Madre Fundadora, Irmã Paulina Paulina do Coração Agonizante de Jesus, abençoou antes de falecer em 09 de julho desse mesmo ano. Segunda-feira, dia 16 de dezembro, comemora-se 154 anos de seu nascimento. Que esta santa, de minha devoção pessoal e familiar, interceda por cada um de vocês, em todo o bom e santo propósito que tiverem e cultivarem; que possam potencializar o que têm de melhor.

Estamos vivendo mais um Advento de Nosso Senhor Jesus Cristo. Vamos sonhar porque acima da terra está a lua; e sobre esta já discorremos em suficiência. Entretanto, acima da lua estão as estrelas. Elas são objeto dos anseios de paternidade e das esperanças de Abraão. Acima das estrelas 
está o céu, de onde a majestade do Pai também sonha: ver o arquétipo da nossa imagem e semelhança no Filho feito carne. Ele nos contempla a todos e aponta para o ventre de Maria onde o mistério envolve, pela união hipostática, em perfeita harmonia, humanidade e divindade. Cada uma, sem perder a essência, enriquecendo-se em nova consistência.

Deus, cosmo e homens, todos ansiamos pela chegada do Emanuel. Florianópolis 14 de Dezembro de 2019. 